\title{
Virtual induction ceremonies: Upholding time-honored tradition
}

\author{
Emily E. Hopkins,' Kathleen C. Spadaro \\ School of Health Sciences, Chatham University, Pittsburgh, PA, USA
}

Received: November 25, 2019

Accepted: January 8, 2020

Online Published: February 24, 2020

DOI: $10.5430 /$ jnep.v10n5p77

URL: https://doi.org/10.5430/jnep.v10n5p77

\begin{abstract}
An induction ceremony is a time-honored tradition among honor societies. Designed to recognize new members and denote transition into the society, induction signifies an important step in formal membership. However, with the growth of online education programs, there is a need for honor societies to adapt from traditional on-ground communities to virtual ones. This adaptation includes conducting an induction ceremony virtually to further create a sense of membership belonging and value. Recognizing the importance of upholding a time-honored tradition, a small private liberal arts university in Southwestern Pennsylvania sought to digitally record their international honor society chapter induction ceremony and share it with their distance inductees via their chapter website. Use of the virtual induction began prior to becoming an international chapter and has continued annually for the past 10 years. Therefore, this experience exchange shares strategies for planning and conducting a successful virtual induction ceremony, thus emphasizing the importance of membership induction for all students especially those online.
\end{abstract}

Key Words: Honor society, Induction ceremony, Virtual, Online education

\section{INTRODUCTION}

Honor societies have long held a place in academics as a way to signify outstanding student performance and recognize exceptional scholarly achievement. Along with the prestige of being invited into an honor society comes the time-honored tradition of the induction ceremony. The induction ceremony provides a venue to showcase the society's prestige and mission along with introducing its newest inductees to current members. With the increase in online educational programs, there has been a need to incorporate extraordinary distance students into honor societies. Recognition of their learning performance is an essential component of academia, demonstrating integrity of the higher educational institution and creating a sense of pride and worth among high achieving nontraditional students. In order to achieve this, an induction ceremony should be held virtually and recorded to share in an asynchronous format. Therefore, the purpose of this article is to share essential components and strategies necessary for planning and conducting a virtual induction ceremony.

\section{BACKGROUND}

The oldest existing college honor society in the United States is Phi Beta Kappa. Phi Beta Kappa was founded at the College of William and Mary, a liberal arts institution, in 1776. ${ }^{[1]}$ National and international honor societies on a collegiate level were developed solely on academic achievement in order to differentiate from campus clubs, sororities and fraternities. Standards set forth by honor societies sought to recognize outstanding student achievement and endorse continued scholarship, leadership, and service activities. To USA.

\footnotetext{
*Correspondence: Emily E. Hopkins; Email: ehopkins@ @hatham.edu; Address: School of Health Sciences, Chatham University, Pittsburgh, PA,
} 
ensure that these societies maintained the standards that were set forth, the Association of College Honor Societies (ACHS) was formed in 1925 through the efforts of several key members of societies that recognized the need for coordination and oversight. ${ }^{[2]}$ The mission of ACHS was to offer national and international honor society members a community that has common goals through certification, a rigorous process that provides credibility and excellence in standards. Therefore, each honor society acknowledges the value of higher education through superior academic achievement and provides member support for growth in leadership, scholarship, research, and service areas. ACHS currently has 70 certified honor societies. A number of disciplines are among these honor societies including engineering, sociology, counseling, pre-medicine, nursing, and lifelong learning. One of the specialty honor societies, Sigma Theta Tau International (Sigma), was founded in 1922 and became an ACHS member in 1959. ${ }^{[3]}$ Sigma promotes excellence in nursing academics and practice through 530 chapters located among 29 countries. $^{[4]}$

Formal induction ceremonies have been part of a timehonored tradition among honor societies. The ceremony signifies new inductees and marks their formal transition into membership while at the same time highlighting the honor society's vision and strengthening relationships among existing members. Receiving an invitation to join and be formally inducted into an honor society is often viewed as prestigious and exclusive by students. Even more so, holding a formal induction ceremony provides an opportunity for students to understand the significance of their academic accomplishment as well as recognize the exclusiveness of society membership. But perhaps mostly importantly, the ceremony adds meaning to becoming a member within the society ${ }^{[5]}$ that can assist with member retention and overall chapter sustainability.

In general, student enrollment in higher education has steadily decreased. Despite this downward trend, online education has continued to flourish and grow. As of 2016 , approximately $31.6 \%$ of all students were taking at least one distance education course and $14.9 \%$ of students were taking online course work exclusively. ${ }^{[6]}$ The nursing profession is not immune to the growth of online education. In fact, the Institute of Medicine (2010) acknowledged that ever-changing progression and demands of health care requires expanded knowledge among nurses. To meet this requirement, they proposed increasing the number of doctoral prepared nurses by two-fold and the number of practicing baccalaureate nurses to $80 \%{ }^{[7]}$ With the Institute of Medicine's call to educate nurses combined with the current and projected shortage of nurses, ${ }^{[8]}$ online education has provided a segue for nurses returning to school. Now nurses can continue clinical practice while at the same time advancing their degree without the disruption of relocation or travel required for a traditional classroom setting. Current data suggests that nationwide there are over $700 \mathrm{RN}$ to BSN programs with at least 600 programs providing online courses. ${ }^{[9]}$ Further, many graduate level nursing programs offer partial or completely online courses with notably $86 \%$ of BSN to MSN and $95 \%$ of DNP programs reporting an online component. ${ }^{[10]}$ The evolution of online learning has presented an opportunity for changing traditional on-ground honor societies to virtual ones that necessitate holding virtual induction ceremonies. To date peer reviewed publications have not addressed this issue.

\section{VIRTUAL INDUCTION CEREMONY}

Nursing faculty at a small private liberal arts university in Southwestern Pennsylvania had the experience of being onground traditional students and were therefore able to experience in-person honor society recognition for academic achievement. Since the university at which they taught consisted of entirely online Baccalaureate, Master's, and Doctoral programs, faculty realized a non-traditional approach was needed to recognize outstanding distance learner student achievement. With a commitment to recognizing excellence among nursing students, these faculty initiated a nursing honor society through their university. Several years later they applied and were accepted for Sigma chapter membership_completing most events online. ${ }^{[11]}$ Understanding the importance of recognition through formal induction processes for members who are nontraditional students, this honor society chapter chose to conduct all induction ceremonies in a format that could be shared virtually.

\section{Components and PLANNing STRATE- GIES FOR A VIRTUAL INDUCTION CERE- MONY}

There are many essential components to consider when planning to perform an induction ceremony virtually. These components include specific chapter needs based on considerations of the academic institution, selection and invitation of inductees, and setting up the ceremony environment. In addition, special attention should be given to ceremony content, ensuring an inviting environment that reflects signature decorum and professionalism. Most importantly, information technology options for digital recording need to be explored and evaluated.

\subsection{Academic institution considerations}

When beginning the induction ceremony planning process, it is important to consider how the honor society chapter is 
established at the academic institution in addition to the chapter's focus. For example, several considerations had to be addressed when forming the virtual induction ceremony for this particular honor society chapter. Given that the university's nursing programs were all online, this Sigma chapter was created specifically for distance members across the US. The identified need was to provide some type of virtual ceremony on an annual basis to reach qualified online nursing students as well as current and original members prior to becoming a Sigma chapter. Although purposefully designed to be virtual, it was still important to make the ceremony personal and honorary-reflecting the values and history of Sigma as well as the University. Therefore, all board members were involved in the planning steps and deciding on an appropriate speaker

\subsection{Selection and invitation of inductees}

The process of identifying qualified students for honor society chapter membership is imperative to ensure that society integrity is maintained and those students achieving academic excellence are appropriately recognized. For this Sigma chapter, steps were followed to make certain that membership aligned with Sigma's requirements. As such, the board member with the role of Counselor requested a list from the nursing program assistant. This list contained nursing students of all three programs that met the chapter and Sigma admission criteria guidelines. The Counselor first reviews the list and then recommends the qualified students to the chapter board. Following board approval, student candidate information is uploaded to the chapter specific Sigma website, and an invitation for membership is sent. Student or graduate candidates can then complete their acceptance form and submit their dues through the parent, Sigma website. However, given that this honor society chapter is centered on virtual membership, additional considerations were made to further create a welcoming atmosphere. This was accomplished by sending a personal candidate invitation email and photograph request from the chapter's Counselor. To create a convivial and professional invitation, careful attention is paid to the writing style and font, and the Sigma chapter logo is used. All candidate photographs received are digitally stored for later use to formally introduce the new inductee during the virtual ceremony.

\subsection{Ceremony environment}

Creating a ceremonial atmosphere is essential for recording the induction ceremony. A formal room, a historical or meaningful setting that sets the tone of significance should be used. The setting should include a table, mantel, or other furniture that can be covered in a white formal table cloth, and hold a formal flower arrangement (this honor society chapter chose silk for re-use), and silver/gold/or crystal candlestick holders and candles. For example, when inducting Sigma members, the signature colors of purple and white are used, the honor society flag set is displayed and honors cords are looped on the tablecloth, along with other memorabilia synonymous with Sigma and the nursing discipline. Board members and the induction ceremony guest speaker present next to this arrangement as a backdrop to enhance inductee and member viewing.

\subsection{Ceremony content}

Often, the honor society website is the best resource for the induction ceremony planning checklists and ceremony script. An example of this is the Sigma honor society website that provides both. ${ }^{[12,13]}$ A PowerPoint presentation is used to provide visual content being shared from the script. When presenting, it is important to introduce chapter board members to assist the new inductee in meeting each one virtually. Therefore, the induction ceremony script is divided among the board members allowing the opportunity for each member to identify themselves and their chapter role prior to presenting induction ceremony content that showcases chapter strengths and opportunities. Of important note, the board members are dressed in business formal attire as if the ceremony was held in person. The invited speaker gives a brief presentation on a relevant topic for the specific honor society discipline. This is followed by the actual induction of new members. All photographs previously received along with the candidate's name, nursing program and city/state they reside are listed on a slide as part of the formal induction ceremony. After one of the board members reads the membership pledge and congratulates the new inductees, a slide with the US map depicting the locations of each of the chapter members is shown to demonstrate chapter outreach and networking across the nation. The conclusion of the ceremony includes information about the chapter's subcommittees, activities and an invitation for new members to participate.

\subsection{Informational technology}

To create a virtual induction ceremony, information technology (IT) resources need to be evaluated. If the chapter is affiliated with a university, there may be an opportunity to tap into student resources through the arts and film discipline. When there is this capacity, the initial contact to the art and film program director/chair allows for discussion and negotiation of services. It would be important to request a student advanced in their studies that can film and also edit as needed. If there is not a discipline specific filming major, many universities have videographers in the IT department that may be available to record the ceremony. It is important 
to allow for advanced notice to ensure that there is availability of these services for the ceremony date identified. In cases where there are not individuals trained in videography available, there are IT applications that can serve the purpose. For example, IT applications such as Panopto, Zoom, and BigBlueButton can be used for recording at little to no cost. All of these applications permit recording and simultaneous screen sharing with the induction ceremony PowerPoint presentation. Once the ceremony is recorded, the link can be sent out to members to watch on their time schedule. ${ }^{[14-16]}$ Many academic institutions have access to these IT applications through their learning management system. However, there are many other video recording possibilities, so when possible it is important to discuss specific video recording needs with the IT specialists in order to choose the best fit. If using technology support, either staff or software, an external microphone for clear recording is essential. To date, several forms of IT have been successfully used when holding this Sigma chapter's virtual induction ceremony. This includes using student videographers and Panopto as well as having a board member with digital recording experience record the virtual induction. While all induction ceremony recording options worked well, those recordings completed with the use of student videographers had the best quality and professional appearance.

\subsection{Ceremony conclusion activities}

Once the induction ceremony recording has been completed, several more steps are required to conclude induction ceremony activities. Most importantly, the digital recording needs to be uploaded to the honor society web site server. If the chapter is using a videographer, that person should convert the video to a flash file that can be transferred to the chapter website server. If an application was used, the recording should be reviewed by the responsible board member (President, WebMaster, or IT chair) for editing as needed prior to placing on the website. After the recorded virtual induction ceremony is finalized and uploaded, the honor society chapter President should send out an email embedded with a link to both new and existing members inviting all to watch and welcome the new inductees. Ideally, this email should also contain a survey link in order to receive member feedback. Board members should also meet and process the experience to determine if any changes are necessary for the next induction ceremony. Finally, a personal thank-you note needs sent to guest speakers-especially if the speaker is an existing chapter member to affirm the society's appreciation and value of their membership.

\section{RECOMMENDATIONS}

Honor societies provide important recognition of academic achievement to students adding worth to resumes and employment opportunities following graduation. Beyond that recognition, membership offers qualified individuals the environment to foster professional development. ${ }^{[17]}$ This includes the ability to network with like-minded peers, leadership opportunities, access to chapter scholarships, and sharing and expanding of research and training opportunities to achieve even greater success. However, students that have chosen to be distance learners due to their personal needs are not always afforded the sense of community that an honor society can bring. An honor society with virtual membership allows for engagement independent of an individual's location, providing the same opportunities as on-ground members.

Table 1. Induction ceremony components and planning strategies

\section{Induction Ceremony Components and Planning Strategies}

Determine New Member Scholarly Criteria and Membership Fee

Create Formal New Member Invitation with a Deadline to Join and Include Date/Time of Induction Ceremony

Once Membership Fee has been collected send request for a personal picture that will be included in the Induction Ceremony

Reserve an appropriate formal setting for recording the Induction Ceremony

Reserve any equipment necessary for recording such as a laptop computer, projector, screen, and microphones

Establish who will record the Induction Ceremony (i.e. Videographer, experienced faculty member, film production student)

Develop Microsoft PowerPoint (PPT) Presentation if one is not available through parent honor society

Determine individual member roles in presentation and if/who will be the guest speaker

Purchase appropriate materials to match the signature style approved by the society to decorate the induction ceremony location Upload digitally recorded induction ceremony to society web site server for viewing

Send out an email announcement to remind existing and new members that induction ceremony is available on society web site Survey newly inducted members and already existing members for their evaluation and critique of the virtual induction ceremony Board members meet to debrief and determine if any changes are needed for the next ceremony

Send out personal thank-you notes to guest speaker 
Engagement of potential members starts with their invitation and induction into the society. Therefore, it is vital to have an organized and professional induction ceremony. A summary of key induction ceremony components and planning strategies have been provided in Table 1. It is essential that both the invitation to join and the induction ceremony are formal and represent the significance of the honor society yet personal to attract and maintain these new inductees. The virtual induction ceremony allows the inductees to "see" the faces of the chapter board members, "hear" their voices as the content of the ceremony is delivered, and "see" themselves and fellow inductees through the slides that have their picture, name and location under each nursing program. The professionally dressed board members and environment are prepared to emphasize the formal and solemn recognition of their achievement - honor society membership based on academic excellence. Furthermore, it affords an opportunity to feel valued and welcomed as a member which may promote membership retention and chapter sustainability. ${ }^{[17]}$

\section{Conclusion}

Honor society induction ceremonies are a momentous occassion signifying academic achievement and the start of official membership. Performing a ceremony provides the opportunity to showcase chapter strengths and enhance member sense of belonging. With the growth of online education, it is necessary to continue student recognition for academic excellence among distance learners. This is accomplished by adapting an honor society chapter to include remote members and upholding the time-honored tradition of induction using a virtual format. By creating a welcoming and professional environment, defining board member participation roles, and utilizing university support for various information technology digital video recording software, a once on-ground and "in-person" only event can be transformed into a virtual ceremony that acknowledges all outstanding student achievement.

\section{CONFLicts OF InTEREST Disclosure}

The authors declare that they have no competing interests.

\section{REFERENCES}

[1] Phi Beta Kappa ratings, reviews and requirements. Is it worth it? [Internet] Washington, DC: Phi Beta Kappa; c2020 [cited 2019 Nov 12]. Available from: https://www.honorsociety.org/phi-b eta-kappa

[2] Moore, ML. Association of college honor societies: Historical information. [Internet] Washington, DC: Phi Beta Kappa; c2020 [cited 2019 Nov 12]. Available from: http://www . achsnatl.org/moo re.asp

[3] ACHS membership directory. [Internet] Okemos: Association of College Honor Societies; c2019 [cited 2019 Nov 12]. Available from: https://www . achsnatl.org/documents/ACHS-Membe $r$-Directory.pdf

[4] Sigma organizational fact sheet. [Internet] Indianapolis: Sigma; c2020 [cited 2019 Nov 12]. Available from: https://www.sigmanursing.org/why-sigma/about-sigma /sigma-organizational-fact-sheet

[5] Ceremonies add meaning to becoming a member. Membership Management Report, 2016 April; 11(4): 5. https://doi.org/10.1002/mmr.30079

[6] Seaman JE, Allen IE, Seaman J. Grade increase: tracking distance education in the United States. [Internet] Oakland: Babson Research Survey Group; c2018 [cited 2019 Nov 12]. Available from: http://www. onlinelearningsurvey.com/highered.html

[7] IOM. The future of nursing: leading change, advancing health. [Internet] Washington DC: National Academy of Sciences; c2020 [cited 2019 Nov 12]. Available from: https: //iom.nationalacademies .org/Reports/2010/The-Futur e-of-Nursing-Leading-Change-Advancing-Health . aspx

[8] AACN: Nursing shortage. [Internet] Washington, DC: American Association of Colleges of Nursing; c2020 [cited 2019 Nov 12]. Available from: https://www . aacnnursing.org/News-Infor mation/Fact-Sheets/Nursing-Shortage

[9] AACN: Creating a more highly qualified nursing workforce. [Internet] Washington, DC: American Association of Col- leges of Nursing; c2020 [cited 2019 Nov 12] Available from: https://www . aacnnursing.org/News-Information/F act-Sheets/Nursing-Workforce

[10] AACN: 2017-2018 enrollment and graduation in baccalaureate and graduate programs in nursing. [Internet] Washington, DC: American Association of Colleges of Nursing; c2020 [cited 2019 Nov 12] Available from: https://www . aacnnursing.org/News-Infor mation/Research-Data-Center/Standard-Data-Reports

[11] Spadaro, KC, Stevens, EE, Doas, M, Wolf, D, Slade, J, Hunker, D. A virtual nursing honor society: recognition for online academic excellence. Journal of Nursing Education and Practice. 2014 Jan; 4(3): 197-203. https://doi.org/10.5430/jnep.v4n3p197

[12] Sigma: Developing honor society induction sample script. [Internet] Indianapolis: Sigma; c2020 [cited 2019 Nov 12]. Available from: https://www.sigmanursing.org/docs/default-source/ chapter-documents/developing-honor-society-inducti on-sample-script. docx?sf vrsn=b5d54cf2_0

[13] Sigma: Induction ceremony checklist. [Internet] Indianapolis: Sigma; c2020 [cited 2019 Nov 12]. Available from: https://www.sigmanursing.org/docs/default-source/ new-chapter-2019/induction-ceremonychecklist_2019. pdf?sfvrsn=21b401f2_2

[14] Panopto: Stop typing. Start recording. [Internet] Panopto; c2020 [cited 2019 Nov 12]. Available from: https://www. panopto.co $\mathrm{m} /$

[15] Zoom for video, conference room, \& phone. [Internet] Zoom; c2020 [cited 2019 Nov 12].

[16] BigBlueButton: Engage your online students. [Internet] BigBlueButton; c2020 [cited 2019 Nov 12]. Available from: https://bigblu ebutton.org/

[17] Hopkins E, Robb M, Fisher M, et al. Honor society membership retention strategies: promoting membership benefits from induction through transition to professional practice. Journal of Nursing Education and Practice. 2016 July; 6(12): 18-23. https : //doi .org/10 .5430/jnep.v6n12p18 